\title{
Simulation of Wellbore Drilling Energy Saving of Nanofluids Using an Experimental Taylor-Couette Flow System
}

\author{
Masoud Rashidi ${ }^{1} \cdot$ Ahmad Sedaghat $^{2} \cdot$ Biltayib Misbah $^{1} \cdot$ Mohammad Sabati $^{3} \cdot$ Koshy Vaidyan $^{1}$. \\ Ali Mostafaeipour ${ }^{4,5,6}$ (1) . Seyyed Shahabaddin Hosseini Dehshiri ${ }^{7} \cdot$ Khalid Almutairi $^{8} \cdot$ Alibek Issakhov $^{9,10}$. \\ Seyed Amir Abbas Oloomi ${ }^{11}$. Mahdi Ashtian Malayer ${ }^{12}$. Joshuva Arockia Dhanraj ${ }^{5,6,13}$
}

Received: 24 May 2021 / Accepted: 25 June 2021 / Published online: 8 July 2021

(C) The Author(s) 2021

\begin{abstract}
Power consumption of wellbore drilling in oil and gas exploitations count for $40 \%$ of total costs, hence power saving of WBM (water-based mud) by adding different concentrations of $\mathrm{Al}_{2} \mathrm{O}_{3}, \mathrm{TiO}_{2}$ and $\mathrm{SiO}_{2}$ nanoparticles is investigated here. A high-speed Taylor-Couette system (TCS) was devised to operate at speeds 0-1600 RPM to simulate power consumption of wellbore drilling using nanofluids in laminar to turbulent flow conditions. The TCS control unit uses several sensors to record current, voltage and rotational speed and Arduino microprocessors to process outputs including rheological properties and power consumption. Total power consumption of the TCS was correlated with a second-order polynomial function of rotational speed for different nanofluids, and the correlated parameters were found using an optimization technique. For the first time, energy saving of three nanofluids at four low volume concentrations $0.05,0.1,0.5$ and $1 \%$ is investigated in the TCS simulating wellbore drilling operation. It is interesting to observe that the lower concentration nanofluids $(0.05 \%)$ have better power savings. In average, for the lower concentration nanofluids $(0.05 \%)$, power was saved by $39 \%, 30 \%$ and $26 \%$ for $\mathrm{TiO}_{2}, \mathrm{Al}_{2} \mathrm{O}_{3}$ and $\mathrm{SiO}_{2} \mathrm{WBM}$ nanofluids, respectively. $\mathrm{TiO}_{2}$ nanofluids have better power saving at lower concentrations of 0.05 and $0.1 \%$, while $\mathrm{Al}_{2} \mathrm{O}_{3}$ nanofluids have saved more power at higher concentrations of 0.5 and $1.0 \%$ compared with their counterpart nanofluids.
\end{abstract}

Keywords Energy saving $\cdot$ Nanofluid $\cdot$ Taylor-Couette system $\cdot$ Water-based mud $\cdot$ Wellbore drilling

\begin{tabular}{ll}
\multicolumn{2}{l}{ Nomenclature } \\
Al2O3 & Aluminum oxide \\
API & American Petroleum Institute \\
API RP 131 & $\begin{array}{l}\text { API Recommended Practice for Laboratory } \\
\text { Testing of Drilling Fluids }\end{array}$ \\
ACK & $\begin{array}{l}\text { Australian College of Kuwait } \\
\text { CT }\end{array}$ \\
DC & Computed tomography \\
FANN & Cirect-current \\
GS & Gel strength \\
HPHT & High-pressure high-temperature \\
APS & Nanoparticle average size \\
OBM & Oil-based mud \\
PV & Plastic viscosity \\
pH & Potential of hydrogen \\
RPM & Rotation per minute
\end{tabular}

Ali Mostafaeipour

mostafaei@yazd.ac.ir

Extended author information available on the last page of the article

$\begin{array}{ll}\mathrm{SiO}_{2} & \text { Silica oxide } \\ \text { SSA } & \text { Specific surface area } \\ \mathrm{TCS} & \text { Taylor-Couette system } \\ \mathrm{TiO}_{2} & \text { Titanium oxide } \\ \mathrm{WBM} & \text { Water-based mud } \\ \text { YP } & \text { Yield point }\end{array}$

\section{Introduction}

Energy plays a big role in human life, and energy supply is one of the most important issues in many societies. The main sources of energy in the world for human life are nonrenewable energy sources, especially oil, methane gas and coal. Oil contributes about $31 \%$, methane gas $21 \%$, coal $29 \%$, nuclear $4.8 \%$ and total renewable energy $10.6 \%$ to the total primary energy supply (Aftab et al. 2017). Today, with the dramatic growth of population and the development of industries, the demand for energy in the world has increased (Almutairi et al. 2021a; Mostafaeipour et al. 2020a). Many 
countries face the problem of supplying energy to meet the demand of the industrial, agricultural and residential sectors (Kalbasi et al. 2021; Mostafaeipour et al. 2020b, c). Energy supply has a great impact on the development of communities, and most of the energy supply in many countries depends on fossil fuels (Mostafaeipour et al. 2020d; Almutairi et al. 2021b). It is projected that two-quarters of the world's energy demand will be met mainly by fossil fuels by 2040 (Aftab et al. 2017). The most possible way to overcome the energy crisis of fossil fuels is to explore and drill more oil and gas wells by 2020 (Aftab et al. 2017). There is continuous interest in reducing exploitation costs in oil and gas industry where $40 \%$ of these costs are related to energy consumption during drilling operations. There are many concerns to maintain safe and trouble-free drilling process particularly at high-pressure high-temperature (HPHT) conditions to protect shale stability and smooth drilling without damage with drilling equipment. For this and other reasons, oil-based mud (OBM) and water-based mud (WBM) should be used and improved by nanoparticles to alleviate tribology and rheology. Reducing friction between rotating surfaces can enhance asperity, contact surfaces and abrasiveness (Booser 1984) while rheology of drilling fluids can be improved by improving characteristics such as gel strength, viscosity, yield point and filtration loss (Chhabra and Richardson 1999).

WBMs are environmentally friendly and preferred fluid over OBMs but will face hard maintenance at HPHT conditions therefore alleviation of WBMs to improve their lubrication will be a key to success of these fluids. Nanoparticles will also enhance thermal, physical, mechanical and chemical characteristics of WBMs (Amanullah and Al-Tahini 2009). In general, smart fluids can be produced using additives including organomolybdenum substances, nanoparticles or organic friction reducers substances (Tang and $\mathrm{Li}$ 2014). Nanofluids are made by adding nanoparticles to the base fluid (here WBM or OBM) using metallic oxides particles of nanosize. Nanoparticles create considerably high surface/volume aspect ratio which improves thermal conductivity and forming atomic layers near to wall surfaces to aggregate slip condition near solid wall surfaces and consequently lubricity, friction and wear (Amanullah and AlTahini 2009).

In drilling industry, nanoparticle of 1-100 nm size was investigated to improve HPHT drilling, avoid pipe sticking, reduce filtration loss and prohibit shale instability (Amanullah and Al-Tahini 2009; Tang and Li 2014; Chai et al. 2015; Shah et al. 2010). Nanoparticle characteristics were considered such as morphology, concentrations, surfactant and presence of magnetic field which showed some tendency to substances with high thermal resistance and biodegradable materials (Amanullah and Al-Tahini 2009). Certain studies at low-speed viscometers (300-600 RPM) turned to show little or no improvements of WBMs by adding $\mathrm{SiO}_{2}, \mathrm{TiO}_{2}$ and $\mathrm{Al}_{2} \mathrm{O}_{3}$ nanoparticles (Jahns 2014). Azaditalab et al. (2016) reported computationally opposite effects at higher speeds. Jabrayilov (2014) showed OBMs reduced significantly friction by silica nanoparticles.

Rheology parameters of interests including GS (gel strength), YP (yield point), PV (plastic viscosity) and filtration loss were reported by Katende et al. (2019) using a FANN Viscometer for $\mathrm{SiO}_{2}$ nanofluids. It was shown some improvement on shale instability and filtration loss using WBM enhanced by some macro-nano additives (Aftab et al. 2017). In addition, certain low-density beads were examined with WBMs for cleaning wellbore by Yeu et al. (2019).

Some studies with WBM nanofluids indicated plastic viscosity (PV) and yield point (YP) were improved and filtration loss, friction torque and lubrication were reduced (Pakdaman et al. 2019). Parizad et al. (2018) and Ponmani et al. (2016) studied different nanoparticles at low concentrations WBM nanofluids on thermal, electrical and filtration loss. A number of studies were conducted with magnetic-type nanoparticles such as $\mathrm{Fe}_{2} \mathrm{O}_{3}$ and $\mathrm{Fe}_{3} \mathrm{O}_{4}$ WBM nanofluids to enhance rheology and filtration loss with significant positive outcomes (Vryzas and Kelessidis 2017; Vryzas et al. 2015, $2016,2017)$ who recommended low concentration nanofluids. Fakoya and Ahmed (2018) found viscosity of WBM is less sensitive than OBM.

The complexity of hydrodynamic of fluid flow in the wellbore drilling operation is due to many factors such as non-Newtonian flow behavior, flow instability patterns, flow transition from laminar to turbulent and eccentricity of the well string (Podryabinkin et al. 2013). Taylor-Couette system (TCS) is a classical rotating compartment that also extensively studied for Newtonian fluids and plenty of complex flow behavior was observed. It is initially introduced by Couette (1890) as a laboratory viscometer and then used by Taylor (1923) for studying flow instabilities. There are growing interests to study TCS in high Reynolds number turbulent flow condition as a powerful tool for examining nonlinear hydrodynamic stabilities and validating new turbulence models (Gils 2011), but it is also of great interest to assess frictional torque at different high Reynolds numbers (Andereck et al. 1986).

In the present work, power saving of nanofluids in wellbore drilling fluids is sought. Power consumption in oil and gas drilling processes constitutes $40-50 \%$ of total costs. Water-based mud (WBM) is one of the favorite's environmentally friendly liquid used in wellbore drilling. Effects of adding nanoparticles to WBM are sought here in terms of power saving. We recently developed a high-speed TCS at ACK (Australian College of Kuwait) to study wellbore drilling fluids by adding nanoparticles (Rashidi et al. 2020a). In the literature, the TCS has mainly used to study flow instabilities and flow patterns, and some TCS devices such as FANN 
viscometers were merely used at a few low speeds below 600 RPM. Thus, one of the objectives of the present study was to devise a high-speed (0-1600 RPM) with exterior transparent acrylic cylinder and the capability of variable speeds and power measurements of accuracy of $\pm 0.01 \mathrm{~W}$. The specification and operations of the TCS are discussed in Sect. 2. Experimental procedure on preparing WBM and nanofluids from three different nanoparticles $\mathrm{Al}_{2} \mathrm{O}_{3}, \mathrm{TiO}_{2}$ and $\mathrm{SiO}_{2}$ is explained in Sect. 3. The objectives are to obtain power consumptions of different nanofluids with very low concentrations of nanoparticles and compare power saving at different speeds. Experimental measurements of power and power-saving patterns of different nanofluids are discussed in Sect. 4. Finally, conclusions are drawn in Sect. 5.

\section{Taylor-Couette flow system}

Taylor-Couette system (TCS) is a classical device for studying fluid flows between two co-axial cylinders. It produces a good platform for assessing energy and turbulence dissipation for the confined cavity fluid in the annulus space between the two cylinders. Couette (Couette 1890) first used the system as a viscometer then Taylor (Chossat and Iooss 2012) used the TCS for studying physics of hydrodynamic stability. Andereck et al. (Andereck et al. 1986) have classified various flow patterns and flow regimes in co- or counter-rotating cylinders. Turbulence modeling can be facilitated since turbulence energy dissipation can be precisely measured using the TCS (Gils 2011). Recently, many other researchers have refocused on different aspects of the TCS such as van Gils (Gils 2011) in highly turbulent Taylor-Couette flow, Grossmann et al. (Grossmann et al. 2016) in high Reynolds number turbulence Taylor-Couette flow, Arias (2015) in torque measurements for laminar and turbulent flows in the TCS, Wang (Wang 2015) and others in fluid visualization using experimental and computational methods.

In cylindrical-type viscometers, the speed of the TCS is usually kept below 600 RPM to avoid complex flow conditions and maintain laminar flow conditions, also to compensate effects of non-Newtonian fluids some calibration formulas implemented. In wellbore drilling, however, the flow condition may vary from laminar to turbulent and eccentric situation between rotating drill and shale may occur. Therefore, we developed a high-speed TCS to be used at ACK (Australian College of Kuwait) for measuring power saving and rheology of non-Newtonian drilling fluids doped with nanoparticles at speeds ranging from 0 to 1600 RPM (see Fig. 1). The capacity of the ACK TCS is $100 \mathrm{ml}$, hence enabling us with a cheap platform for studying non-Newtonian nanofluids for improvements of power consumption and

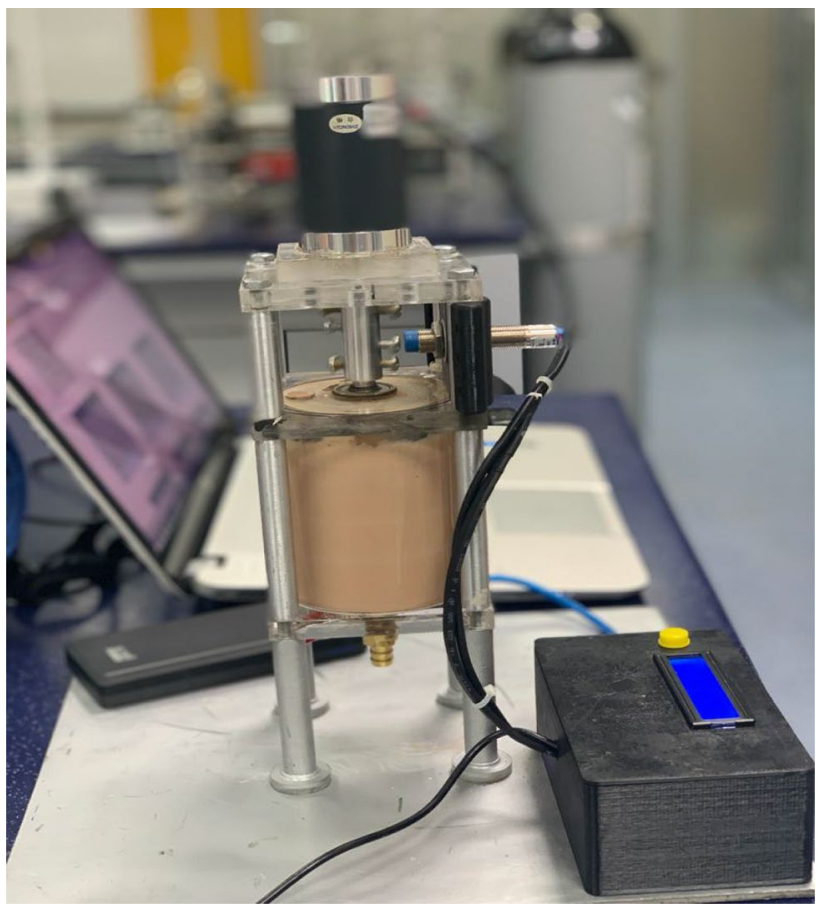

Fig. 1 ACK Taylor-Couette system (TCS) (Rashidi et al. 2020a)

Table 1 Main sizes and features of the ACK TCS (Rashidi et al. 2020a)

\begin{tabular}{ll}
\hline Parameters & Values \\
\hline Material of inner cylinder & Stainless steel \\
Material of outer cylinder & Acrylic \\
Electric DC motor speed range & $0-1600 \mathrm{RPM}$ \\
Inner cylinder radius $\left(R_{\mathrm{i}}\right)$ & $34 \mathrm{~mm}$ \\
Outer cylinder radius $\left(R_{\mathrm{o}}\right)$ & $38 \mathrm{~mm}$ \\
Gap width $(\delta)$ & $4 \mathrm{~mm}$ \\
Wet length of cylinder $(L)$ & $110 \mathrm{~mm}$ \\
Wet annulus volume $(\forall)$ & $100 \mathrm{ml}$ \\
Thickness of outer cylinder & $3 \mathrm{~mm}$ \\
\hline
\end{tabular}

rheology of drilling fluids in oil and gas industry. Table 1 provides sizes and features of the developed ACK TCS.

The developed ACK TCS consists of two concentric vertical cylinders with acrylic outer shell cylinder and stainless steel solid inner cylinder. The inner cylinder is seated from top and bottom on two bearing and sealing system and connect from top side to an electric DC (direct-current) motor (see Fig. 2). The speed of the ACK TCS is controlled by a rheostat to provide speeds from 0 to 1600 RPM. The acrylic outer cylinder is fixed and stationary. Fluid is supplied from the top using a funnel and discharged at the bottom from a barbed fitting. The ACK TCS is equipped with sensors to measure voltage, current, and frequency of rotating shaft of

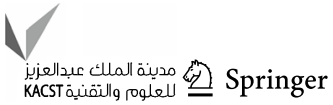




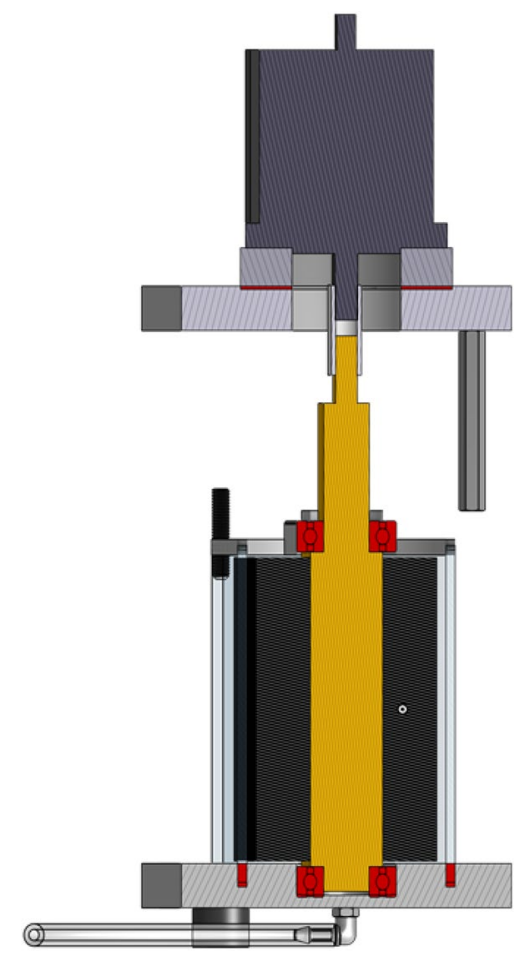

Fig. 2 CAD design of the Taylor-Couette System (Rashidi et al. 2020a)

DC motor from which power, viscosity and rotational speed (in RPM and rad/s) are determined using multiple Arduino microprocessors and monitored using an LCD display.

\section{Methodology}

In the present work, the ACK TCS was used to determine power saving of WBM nanofluids. The methodology includes preparation of API standard WBM, preparation of various volume fractions of three different nanoparticles: aluminum oxide $\left(\mathrm{Al}_{2} \mathrm{O}_{3}\right)$, titanium oxide $\left(\mathrm{TiO}_{2}\right)$ and silica $\left(\mathrm{SiO}_{2}\right)$ nanoparticles to $\mathrm{WBM}$, testing the nanofluids in the ACK TCS at different rotational speeds for measuring electrical power consumption and modelling power saving of different concentration WBM nanofluids. Details of the above enlisted methodology are discussed next.

\section{WBM preparation}

In order to study non-Newtonian drilling fluids, we used water-based mud (WBM) and prepared it according to the standard API RP 131 (13B-1 AR (2009)) procedure using $4 \%$ bentonite and distill (or de-ionized) water taking the steps: (1) $350 \mathrm{ml}$ of the distill water was mixed with $15 \mathrm{~g}$ of the bentonite at room temperature of $21^{\circ} \mathrm{C},(2)$ mixer wall was cleaned from sticked bentonite every 5 min and (3) the steps repeated for $20 \mathrm{~min}$.

\section{Nanomaterial selection}

Nanoparticles in aqueous solutions produce a protective film near solid surfaces. The protective film has low-elastic modulus/low-hardness which enhances significantly lubrication properties (Yu and Xie 2012). Nanoparticles are crystalized materials that usually have high-hardness and heat/wear resistance. The extremely small size and shape of nanoparticles allow them entering small spaces in the solid contact surfaces without changing hydrodynamic of the flow (Luo et al. 2014). By pressure action of nanofluids, nanoparticles enter spaces on the solid contact surface forming a self-protective film, which results in micro-polishing and self-mending surface that yields to friction reductions. This protective layer is the key on reducing wear of drilling strings and decreased energy consumptions. In addition, spherical shape nanoparticles have additional ball-bearing effects that reduces sliding contact surface into smaller rolling surface contacts particularly at high-pressure operation that improves considerably lubrications (Luo et al. 2014). Nanofluids provide higher conductivity, higher boiling-point and improved viscosity properties. Stabilization of nanoparticles is challenging in aquas suspensions, and stability of nanofluids in practical conditions is among technological concerns of nanofluids (Huang et al. 2009). Some studies show that stability of nanoparticles may depend on electrokinetic properties and well-dispersed suspension are achievable by electrostatic repulsion force in agreement with the DLVO theory (Huang et al. 2009). Surfactants are used to stabilize nanofluids yet may cause several issues such as creation of foams in heat transfer media which attached to the surface of nanoparticles causing decreased effective thermal conductivity. Nanoparticles alter thermal properties and heat transfer performance of nanofluids by three physical mechanisms: the particle-fluid interfacial interaction layers, particle aggregation in static mode and Brownian motion in dynamic mode (Yu et al. 2010).

In order to prepare a nanofluid, it is important to select nanoparticles based on suitability, availability, cost, and also research purpose. There are various types of nanoparticles used in nanofluids particularly metals, metal oxides and carbon.

Silica nanoparticles are usually either P-type or S-type. S-type nanoparticles which are nearly spherical shapes were used for this study. The P-type silica nanoparticles are porous with much larger surface specific area. The $\mathrm{Al}_{2} \mathrm{O}_{3}$ nanoparticles were purchased from nanostructured and amorphous materials, Inc (Aluminum Oxide 2019). Available specification of these nanoparticles is shown in Table 2. 
Table 2 Nanomaterials specification

\begin{tabular}{llll}
\hline Nanoparticles & $\mathrm{TiO}_{2}$ & $\mathrm{Al}_{2} \mathrm{O}_{3}$ & $\mathrm{SiO}_{2}$ \\
\hline Purity & $99.9 \%$ & $99.5 \%$ & $99.5 \%$ \\
Type & Anatase & - & S-type \\
Shape & - & Nearly spherical & Near spherical particles \\
Color & White & White & White \\
Nanoparticle average size (APS) & $18 \mathrm{~nm}$ & $27-43 \mathrm{~nm}$ & $30-50 \mathrm{~nm}$ \\
Specific surface area (SSA) & $200-240 \mathrm{~m}^{2} / \mathrm{g}$ & $35 \mathrm{~m}^{2} / \mathrm{g}$ & $30-80 \mathrm{~m}^{2} / \mathrm{g}$ \\
Relative density & $4.23 \mathrm{~g} / \mathrm{cm}^{3}$ & $3.5-3.9 \mathrm{~g} / \mathrm{cm}^{3}$ & $2.4 \mathrm{~g} / \mathrm{cm}^{3}$ \\
Manufacturing method & High-temperature & - & High-temperature combustion \\
& combustion & \\
\hline
\end{tabular}

Transmission electron microscopy (TEM) images of the selected nanoparticles are shown in Fig. 3.

The size of nanoparticles also varies from 10 to $100 \mathrm{~nm}$, and shape of nanoparticles varies from spherical, rod, tube, disk, and so on or irregular shapes. In a known nanopowder, the size of nanoparticles is varied and usually the average size is given (see Table 2). The aim of this study is to investigate rheology of nanofluids on friction reduction, hence,
Fig. 3 Transmission electron microscopy (TEM) of studied nanoparticles

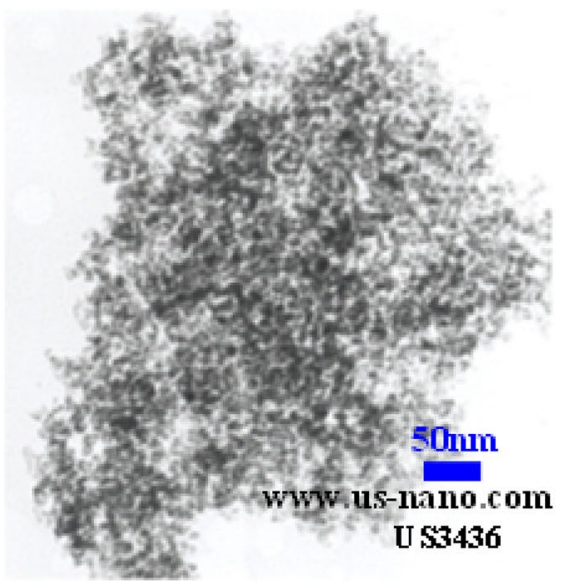

TEM of silica nanoparticles [53]

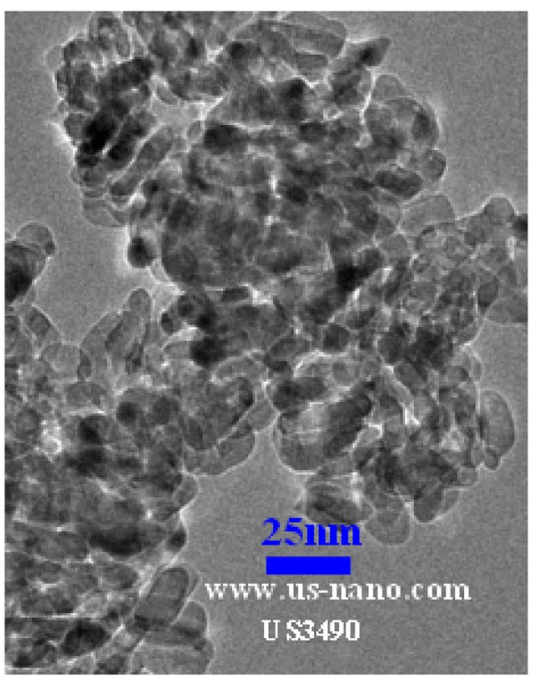

TEM of titanium nanoparticles [53]

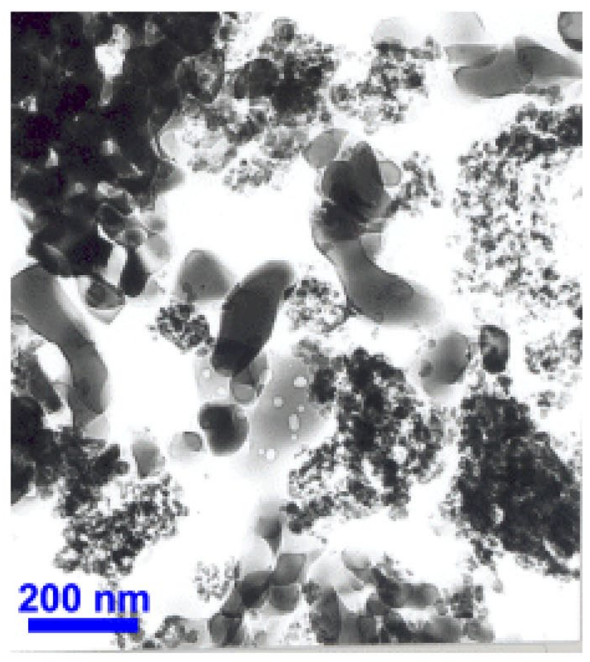

TEM of alumina nanoparticles [54] 
aluminum oxide $\left(\mathrm{Al}_{2} \mathrm{O}_{3}\right)$, titanium oxide $\left(\mathrm{TiO}_{2}\right)$ and silica $\left(\mathrm{SiO}_{2}\right)$ nanoparticles were selected. The silica (product no. US3440) and titanium (product no. US3490) nanoparticles were obtained from US Research Nanomaterials company (Silicon Oxide Nanopowder 2019). Table 2 provides properties of the nanopowders used in this work.

\section{Mass of nanoparticles}

We used Einstein model to determine the density of nanofluids given by (Larson 1983; Wiener 1912):

$\rho_{\mathrm{nf}}=\rho_{\mathrm{p}} \phi+\rho_{\mathrm{bf}}(1-\phi)$

In Eq. (1), $\rho_{\mathrm{bf}}, \rho_{\mathrm{nf}}$ and $\rho_{\mathrm{P}}$ are densities of base fluid, nanofluid and nanoparticles, respectively, and $\phi$ represents concentration or volume fraction of nanoparticles. Mass of nanoparticles in grams can be determined using:

$m_{\mathrm{np}}(g)=\left(\frac{\phi}{100-\phi}\right) \frac{\rho_{\mathrm{np}}}{\rho_{\mathrm{bf}}} m_{\mathrm{bf}}(g)$

As an example, for preparing $100 \mathrm{ml} \mathrm{TiO}_{2}$ nanofluid with concentration of $\phi=0.1 \%\left(\rho_{\mathrm{np}}=4.3 \mathrm{~g} / \mathrm{ml}\right)$ in water $\left(\rho_{\mathrm{bf}}=1 \mathrm{~g} /\right.$ $\mathrm{ml}$ ), we need $m_{\mathrm{np}}=4.3 \mathrm{~g}$ nanoparticles.

\section{Nanofluid preparation}

In one-step method, nanoparticles are directly dispersed in the base fluid in the process of producing them. Nanoparticles are either in form of vapor or liquid chemicals that are dispersed in the base fluid while converting to them solid particles. Nanoparticle dispersion in base fluid is improved, and agglomeration is reduced to minimum in this technique. However, we used a two-step method which is widely practiced because of its ease in preparation. In the first-step, nanoparticles are prepared in the form of dry powder. In the second step, nanoparticles are mixed with base fluid in an ultrasonic mixer.

In this work, we studied nanofluids with volume concentrations of $0.05,0.1,0.5,1$, and $3 \%$. To measure mass of nanoparticles, we used a digital scale $200 \times 0.001 \mathrm{~g}$ with accuracy of $1 \mathrm{mg}$, i.e., Lab Analytical Balance Digital High Precision Electronic Scale Jewelry Scale. The scale was calibrated using provided $100 \mathrm{~g}$ standard mass before measuring any nanopowder. The measured mass of nanoparticles was transferred to the mixing container, and then, $100 \mathrm{ml}$ of WBM was added.

The optimum way to apply ultrasonic mixer depends on mixer power and frequency level, nanoparticles type and volume concentration, base fluid, time of mixing and so on.

Afzal et al. (2019) hinted out that there is an optimum ultrasonication time depending on the factors counted above. In the present work, we used $45 \mathrm{~min}$ as the mixing time at temperatures below $40{ }^{\circ} \mathrm{C}$ (cooled by ice or cold water) and power level below $300 \mathrm{~W}$ to avoid damage to molecular structure of nanoparticles and also to prohibit coagulations of nanoparticles in the fluid.

Hangzhou Dowell ultrasonic mixer model (DW20-1500A) was used which is $1500 \mathrm{~W}$ variable power mixer (AC, $220 \mathrm{~V}, 50 \mathrm{~Hz}$ ) for preparing nanofluids based on the above instructions. Prepared nanofluid is then transferred to TCS to get readings at different speeds. The ACK TCS uses an entry hole to be filled in from the top and exit hose at the bottom to discharge test fluids using multiple wash by water and allow to dry. All processes described above are shown in Fig. 4.

In this work, we prepared nanofluids with volume concentrations of $0.05,0.1,0.5$, and $1 \%$ using WBM $(4 \%$ vol Bentonite API Standard $\left(\rho_{\mathrm{bf}}=1.03051 \mathrm{~g} / \mathrm{ml}\right)$ and nanoparticles listed in Table 3. Using Eq. (2), the amount of nanopowders (in grams) are obtained for each nanofluid and listed in Table 3. For alumina nanoparticles, the measured density $\left(\rho_{\mathrm{np}}=3.88 \mathrm{~g} / \mathrm{ml}\right)$ was used. The accuracy of our digital scale was $1 \mathrm{mg}$; therefore, the measurements of nanopowders were done according to the values given in Table 3. Next, the prepared WBM and WBM nanofluids were tested in the ACK TCS at speeds from 200 to 1600 RPM with interval of 200 RPM. After experiments, the TCS was washed with water and dried.

\section{Experimental results and discussions}

The goal of the present study is to correlate the power consumption of the ACK TCS using WBM fluids with and without nanoparticles versus the rotational speed. To be ensure the accuracy of the TCS, it is first calibrated versus an Anton-Paar rheometer; then, all raw measurements of power consumptions with the accuracy of $\pm 0.01 \mathrm{~W}$ are reported in Tables 4, 5 and 6. Next, the modelling of the measured power consumption with a polynomial function and accuracy of the fitting functions are expressed in Table 7 and the results of power savings are presented for each nanofluids.

\section{Calibration of the ACK TCS}

In order to ensure that the ACK TCS can accurately produce rheological properties of interests, the consistency chart and the apparent viscosity measurements are compared with a high precision rheometer (Anton-Paar MCR302 rheometer) data reported by Kristensen (Kristensen 2013) and the results are shown in Fig. 5.

Figure 5 shows that the ACK TCS has accurately calibrated against the high precision rheometer data for the WBM (4\% API standard) and can provide reliable and accurate results. Details on determination of the rheological 
Fig. 4 Steps for preparing and testing WBM nanofluids in the ACK TCS (Rashidi et al. 2020a)

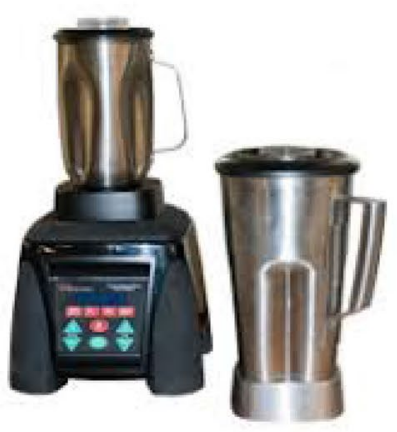

\section{WBM Mixer}

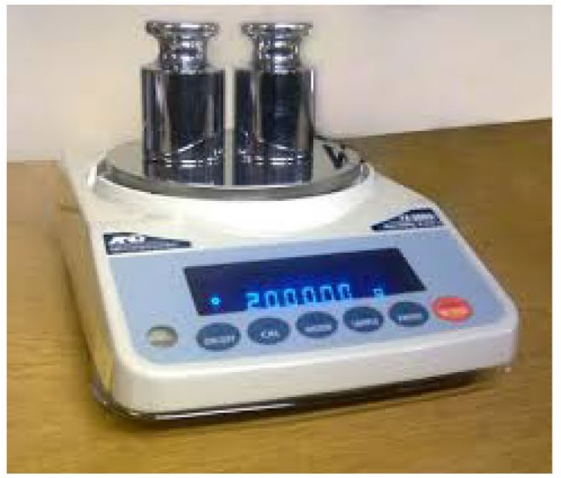

2. Digital Scale

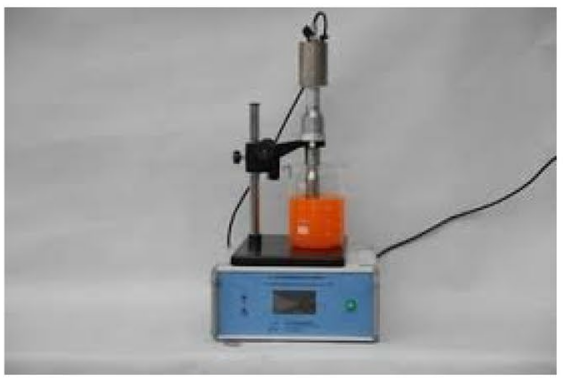

3. Ultrasonic Generator

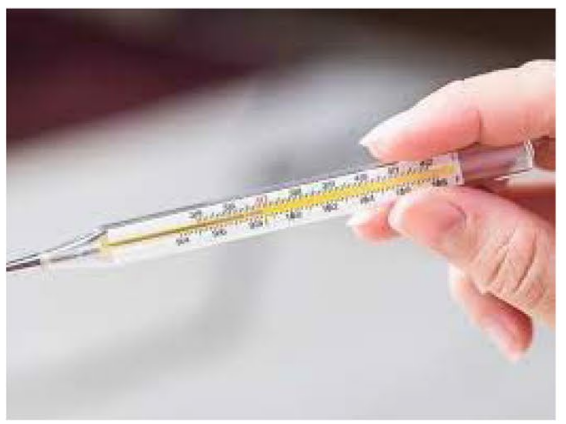

\section{Thermometer}

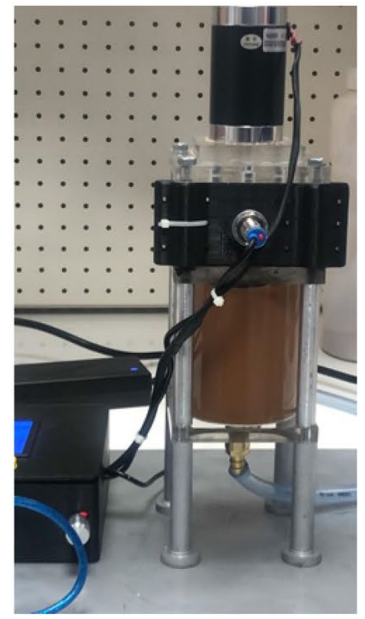

5. ACK Taylor-Couette Device

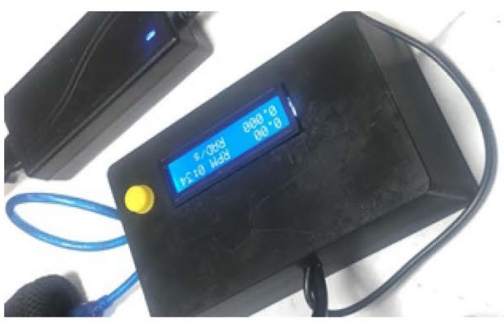

6. Control Display Unit
Table 3 Mass of nanoparticles for $100 \mathrm{ml} \mathrm{WBM} \mathrm{(4 \%} \mathrm{vol} \mathrm{Bentonite}$ API Standard) nanofluid

\begin{tabular}{llll}
\hline$\phi(\%)$ & $\mathrm{TiO}_{2}(\mathrm{~g})$ & $\mathrm{Al}_{2} \mathrm{O}_{3}(\mathrm{~g})$ & $\mathrm{SiO}_{2}(\mathrm{~g})$ \\
\hline 0.05 & 0.212 & 0.194 & 0.120 \\
0.1 & 0.423 & 0.388 & 0.240 \\
0.5 & 2.126 & 1.950 & 1.206 \\
1 & 4.273 & 3.919 & 2.424 \\
\hline
\end{tabular}

parameters in Fig. 5 from power measurement and accuracy were reported by Rashidi et al. (2020b).

\section{Power measurements}

The ACK TCS is a good tool to observe power saving of nanoparticles when added to a base fluid particularly at high rotational speeds. TCS was first filled with WBM (4\% vol Bentonite API Standard) to obtain total power due to the 
Table 4 Total power measurements of the ACK TCS for $\mathrm{Al}_{2} \mathrm{O}_{3}$ nanofluids; from Rashidi et al. (2020b)

\begin{tabular}{|c|c|c|c|c|c|c|c|}
\hline \multicolumn{2}{|c|}{$\mathrm{Al}_{2} \mathrm{O}_{3}(0.05 \mathrm{vol} \%)$} & \multicolumn{2}{|c|}{$\mathrm{Al}_{2} \mathrm{O}_{3}(0.1 \mathrm{vol} \%)$} & \multicolumn{2}{|c|}{$\mathrm{Al}_{2} \mathrm{O}_{3}(0.5 \mathrm{vol} \%)$} & \multicolumn{2}{|c|}{$\mathrm{Al}_{2} \mathrm{O}_{3}(1.0$ vol $\%)$} \\
\hline Speed (rad/s) & Power (W) & Speed (rad/s) & Power (W) & Speed (rad/s) & Power $(\mathrm{W})$ & Speed (rad/s) & Power (W) \\
\hline 20.53 & 4.04 & 21.47 & 4.07 & 20.78 & 4.44 & 20.99 & 5.04 \\
\hline 45.26 & 9.17 & 51.93 & 11.29 & 40.82 & 8.32 & 47.06 & 10.10 \\
\hline 64.77 & 14.66 & 64.61 & 15.63 & 55.33 & 15.87 & 63.55 & 16.46 \\
\hline 84.10 & 19.74 & 84.61 & 23.00 & 85.62 & 24.03 & 83.86 & 24.87 \\
\hline 105.50 & 27.00 & 125.81 & 39.60 & 125.75 & 39.26 & 113.66 & 39.12 \\
\hline 126.70 & 35.60 & 144.81 & 48.12 & 146.54 & 49.72 & 146.64 & 55.03 \\
\hline 129.12 & 37.70 & 168.15 & 58.10 & 172.32 & 62.46 & 168.06 & 68.29 \\
\hline 172.20 & 52.60 & & & & & & \\
\hline
\end{tabular}

Table 5 Total power measurements of the ACK TCS for $\mathrm{TiO}_{2}$ nanofluids

\begin{tabular}{|c|c|c|c|c|c|c|c|}
\hline \multicolumn{2}{|c|}{$\mathrm{TiO}_{2}(0.05 \mathrm{vol} \%)$} & \multicolumn{2}{|c|}{$\mathrm{TiO}_{2}(0.1$ vol\%) } & \multicolumn{2}{|c|}{$\mathrm{TiO}_{2}(0.5$ vol $\%)$} & \multicolumn{2}{|c|}{$\mathrm{TiO}_{2}(1.0 \mathrm{vol} \%)$} \\
\hline Speed $(\mathrm{rad} / \mathrm{s})$ & Power (W) & Speed $(\mathrm{rad} / \mathrm{s})$ & Power (W) & Speed $(\mathrm{rad} / \mathrm{s})$ & Power (W) & Speed $(\mathrm{rad} / \mathrm{s})$ & Power (W) \\
\hline 22.84 & 3.50 & 11.77 & 4.17 & 23.56 & 6.59 & 25.41 & 6.52 \\
\hline 42.40 & 7.18 & 32.95 & 7.16 & 47.11 & 9.58 & 52.04 & 13.62 \\
\hline 63.30 & 13.00 & 62.33 & 14.18 & 65.89 & 15.40 & 83.23 & 24.82 \\
\hline 84.50 & 19.50 & 127.01 & 41.81 & 83.41 & 21.85 & 125.30 & 41.34 \\
\hline 104.81 & 25.80 & 148.53 & 50.01 & 103.18 & 29.63 & 149.87 & 51.21 \\
\hline 126.98 & 35.63 & 169.78 & 57.17 & 124.33 & 37.19 & 171.62 & 59.99 \\
\hline 150.50 & 46.80 & & & 147.77 & 47.57 & & \\
\hline 175.30 & 57.50 & & & & & & \\
\hline
\end{tabular}

Table 6 Total power measurements of the ACK TCS for $\mathrm{SiO}_{2}$ nanofluids

\begin{tabular}{|c|c|c|c|c|c|c|c|}
\hline \multicolumn{2}{|c|}{$\mathrm{SiO}_{2}(0.05$ vol $\%)$} & \multicolumn{2}{|c|}{$\mathrm{SiO}_{2}(0.1$ vol\% $)$} & \multicolumn{2}{|c|}{$\mathrm{SiO}_{2}(0.5$ vol\% $)$} & \multicolumn{2}{|c|}{$\mathrm{SiO}_{2}(1.0 \mathrm{vol} \%)$} \\
\hline Speed $(\mathrm{rad} / \mathrm{s})$ & Power (W) & Speed $(\mathrm{rad} / \mathrm{s})$ & Power (W) & Speed $(\mathrm{rad} / \mathrm{s})$ & Power (W) & Speed $(\mathrm{rad} / \mathrm{s})$ & Power (W) \\
\hline 21.75 & 4.44 & 20.13 & 4.83 & 21.76 & 5.19 & 21.14 & 5.41 \\
\hline 41.42 & 8.80 & 43.14 & 10.12 & 43.14 & 10.20 & 42.15 & 10.05 \\
\hline 53.34 & 15.20 & 62.30 & 16.10 & 64.54 & 17.50 & 63.40 & 16.99 \\
\hline 82.73 & 19.60 & 101.20 & 28.76 & 84.50 & 25.00 & 84.10 & 24.94 \\
\hline 107.30 & 28.32 & 104.10 & 28.80 & 104.65 & 31.30 & 105.10 & 31.81 \\
\hline 129.00 & 35.40 & 107.40 & 38.80 & 126.50 & 40.80 & 127.40 & 42.78 \\
\hline 150.80 & 44.00 & 146.10 & 48.37 & 147.80 & 50.80 & 149.70 & 53.28 \\
\hline 166.70 & 50.80 & 174.26 & 61.39 & 173.80 & 63.20 & 170.10 & 62.51 \\
\hline
\end{tabular}

base fluid. Then, nanofluids with different concentrations were tested to measure total power due to nanofluids. The results for power measurements for the studied nanofluids at different speeds are summarized in Tables 4, 5 and 6. In order to achieve steady-state flow condition in TCS, the speed controller was set to a certain value and TCS was allowed to operate for $10 \mathrm{~min}$ or more and then speed and power was recorded.

It was observed that the total power of all non-Newtonian fluids in the ACK TCS can be fitted well with a secondordered polynomial as follows (Rashidi et al. 2020a):
$\mathrm{P}_{\mathrm{WBM}}=a \Omega_{\mathrm{i}}^{2}+b \Omega_{\mathrm{i}}$

The coefficients in Eq. (3) for all studied fluids were found using an optimization algorithm (fminsearch) in MATLAB and are provided in Table 7. Details of the optimization method were reported in our previous publication (Rashidi et al. 2020b). Also, the coefficient of determination $R^{2}$ on the accuracy of the fit functions is given in Table 7. In Eq. (3), $\Omega_{\mathrm{i}}$ (RPM) is the speed of inner cylinder. Power saving of different nanofluids is then estimated using: 
Table 7 Coefficients of fitting function in Eq. (3) to the total power and accuracy

\begin{tabular}{lllll}
\hline Fluid & $\begin{array}{l}\text { Volume frac- } \\
\text { tion } \phi(\%)\end{array}$ & \multicolumn{2}{l}{$\begin{array}{l}\text { Coefficients of the 2nd } \\
\text { order polynomial }\end{array}$} & $\begin{array}{l}\text { The coefficient of } \\
\text { determination }\left(\mathrm{R}^{2}\right)\end{array}$ \\
\cline { 3 - 4 } & & $\mathrm{a}$ & $\mathrm{b}$ & \\
\hline $\mathrm{WBM}$ & $\mathrm{NA}$ & $1.0 \mathrm{E}-05$ & 0.0281 & 0.9989 \\
$\mathrm{Al}_{2} \mathrm{O}_{3}$ & 0.05 & $8.0 \mathrm{E}-06$ & 0.0189 & 0.9970 \\
& 0.1 & $1.0 \mathrm{E}-05$ & 0.0192 & 0.9988 \\
& 0.5 & $1.0 \mathrm{E}-05$ & 0.0211 & 0.9978 \\
& 1.0 & $1.0 \mathrm{E}-05$ & 0.0188 & 0.9988 \\
$\mathrm{TiO}_{2}$ & 0.05 & $1.0 \mathrm{E}-05$ & 0.0139 & 0.9990 \\
& 0.1 & $9.0 \mathrm{E}-06$ & 0.0223 & 0.9942 \\
& 0.5 & $1.0 \mathrm{E}-05$ & 0.019 & 0.9960 \\
& 1.0 & $7.0 \mathrm{E}-06$ & 0.0257 & 0.9992 \\
$\mathrm{SiO}_{2}$ & 0.05 & $7.0 \mathrm{E}-06$ & 0.0211 & 0.9949 \\
& 0.1 & $8.0 \mathrm{E}-06$ & 0.0235 & 0.9816 \\
& 0.5 & $1.0 \mathrm{E}-05$ & 0.0224 & 0.9995 \\
& 1.0 & $1.0 \mathrm{E}-05$ & 0.0223 & 0.9991 \\
\hline
\end{tabular}

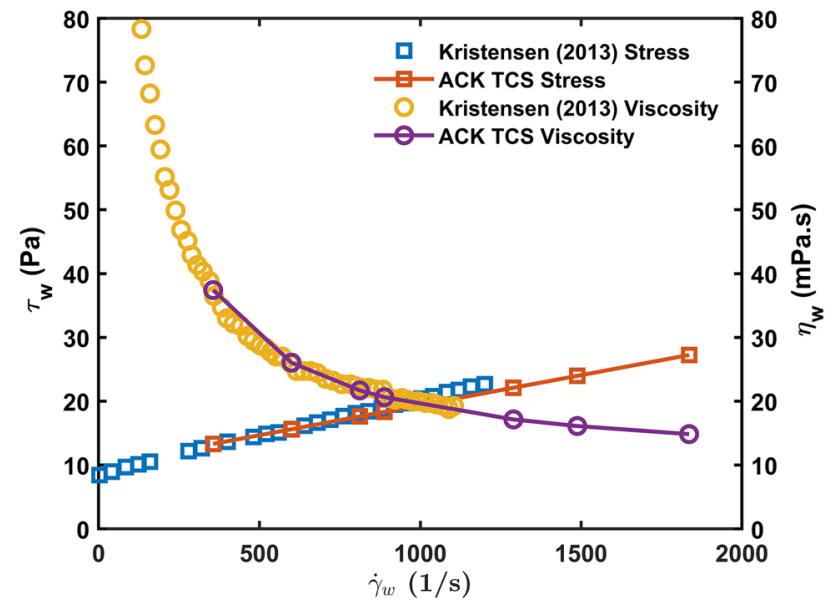

Fig. 5 Accuracy of the ACK TCS versus an Anton-Paar MCR302 rheometer data (Kristensen 2013)

Power saving $=\frac{P_{\mathrm{WBM}}-P_{\mathrm{nf}}}{P_{\mathrm{WBM}}} \times 100 \%$

In Eq. (4), $P_{\mathrm{WBM}}$ and $P_{\mathrm{nf}}$ are WBM total power and the nanofluid total power, respectively.

Table 7 values for the total power were used to present power-saving values at exact speed intervals of 200, 400, $600,800,1000,1200,1400$ and 1600 RPM. First, the raw results of the total power for each fluid are presented and then power saving for different concentration of nanofluids is given. Next, a comparison of power saving is made among the studied nanofluids.

\section{Power consumption and power saving of $\mathrm{Al}_{\mathbf{2}} \mathrm{O}_{\mathbf{3}}$ nanofluids}

The total power consumption of the $\mathrm{Al}_{2} \mathrm{O}_{3}$ nanofluids when mixed with the base fluid (WBM) is compared in Fig. 6 . All the nanofluids showed a reduction in power consumption of the TCS as shown in the results. $\mathrm{Al}_{2} \mathrm{O}_{3}(0.05 \mathrm{vol}$ $\%$ ) which corresponds to the lowest concentration studied here interestingly observed the lowest power consumption. Equation (4) is used to calculate the total power saving of $\mathrm{Al}_{2} \mathrm{O}_{3}$ nanofluids taken at different volumes and is shown in Fig. 6. It is interesting to observe that higher power savings are obtained when the TCS was operated at lower speeds and for lower concentration of $\mathrm{Al}_{2} \mathrm{O}_{3}$ nanofluids.

For $\mathrm{Al}_{2} \mathrm{O}_{3}$ concentrations of $0.05,0.1,0.5$ and 1.0 at $200 \mathrm{RPM}$, a total power saving of $31.89,29.57,23.26$ and $30.90 \%$, respectively, was obtained as shown in Fig. 7. The highest power saving is observed for the low-speed cases where the lowest concentration of $0.05 \%$ is considered as the best followed by second lowest concentration of $1.0 \%$ considered as the second best. By increasing the speed of the TCS, it can be observed that the total power saving of the remaining concentrations shows a decreasing trend. For instance, appreciable total power savings of 28.12, 20.18, 15.87 and $21.09 \%$ is obtained for higher speeds of 1600 RPM but they are lower when compared with the 200 RPM total power savings. As indicated earlier in the results, lower $\mathrm{Al}_{2} \mathrm{O}_{3}$ concentration of $0.05 \%$ performed the best among all concentrations (see Fig. 7).

\section{Power consumption and power saving of $\mathrm{TiO}_{2}$ nanofluids}

Figure 8 shows power consumptions in the ACK TCS testing by using different concentrations of $\mathrm{TiO}_{2}$ nanofluids. The results obtained are also compared with the total power of the base fluid.

As observed in Fig. 8, all nanofluids have reduced power consumptions of the WBM base fluids at all speeds and all concentrations, although results indicate that $\mathrm{TiO}_{2}(0.05 \mathrm{vol}$ $\%$ ) consumed lowest power for all speeds.

Figure 9 shows different energy saving patterns when compared to the trends obtained for $\mathrm{Al}_{2} \mathrm{O}_{3}$ nanofluids. Trends of total power savings of $\mathrm{TiO}_{2}$ WBM nanofluids showed fast decreasing trends for low concentration and slow decreasing or increasing trends for higher concentrations as shown in Fig. 9 for all speed ranges of the ACK TCS. Higher power saving is observed at lower speeds. For example, at speed of 200 RPM, the power saving of 47.18 , 19.93, 30.23 and $9.97 \%$ is observed for $\mathrm{TiO}_{2}$ concentrations of $0.05,0.1,0.5$ and 1.0, respectively. The power saving $47.18 \%$ for $\mathrm{TiO}_{2}(0.05 \mathrm{vol} \%)$ was the highest power saving among all of the studied nanofluids and concentrations.

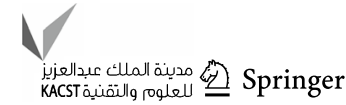


Fig. 6 Total power consumption of $\mathrm{Al}_{2} \mathrm{O}_{3}$ WBM nanofluids in the ACK TCS
Fig. 7 Total power saving of $\mathrm{Al}_{2} \mathrm{O}_{3}$ WBM nanofluids in the ACK TCS
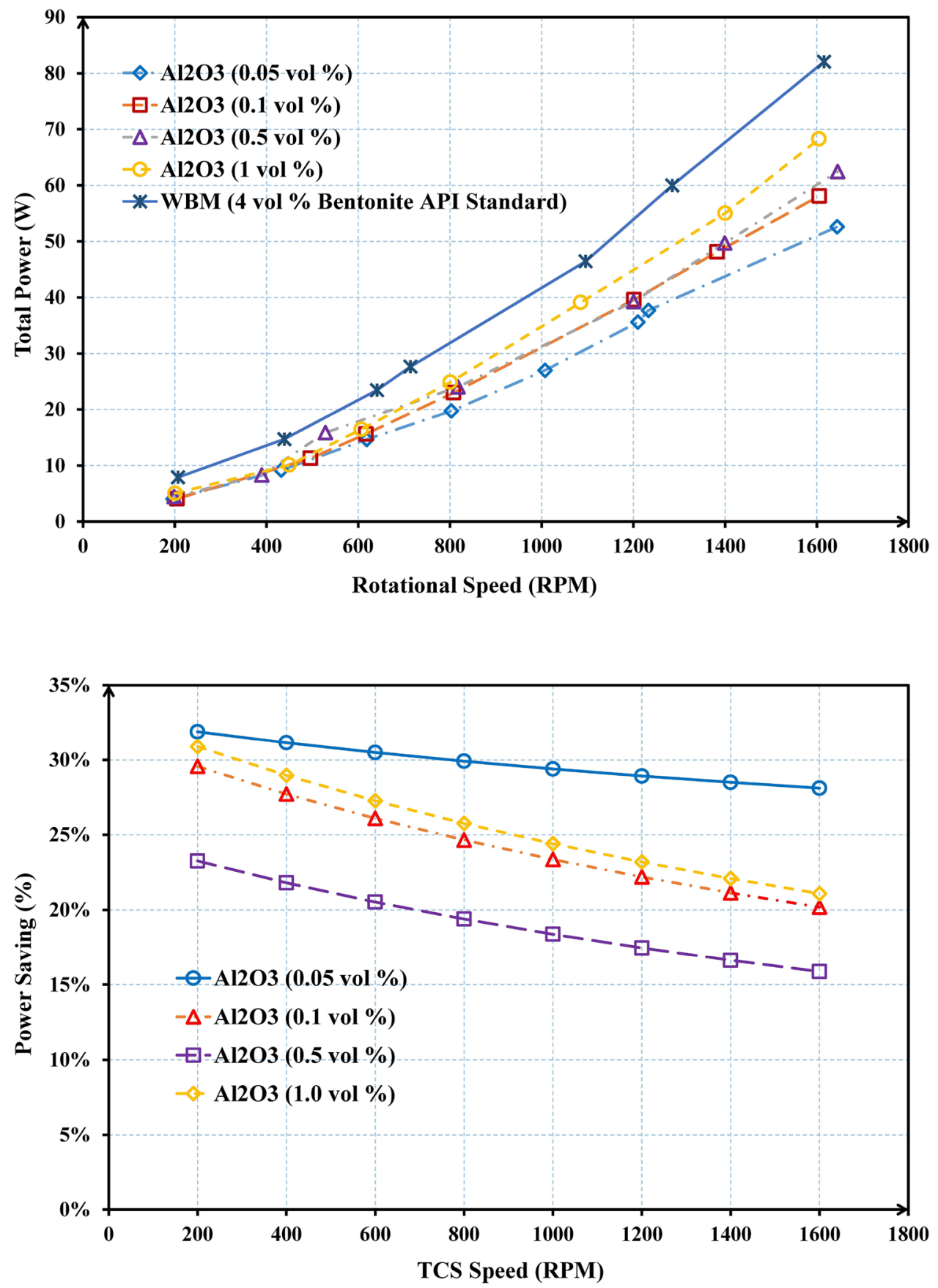

\section{Power consumption and power saving of $\mathrm{SiO}_{2}$ nanofluids}

Figure 10 shows power variations in TCS using $\mathrm{SiO}_{2}$ nanofluids at different speeds. It is interesting to observe that two other nanofluids showed similar trends as discussed above and their power consumptions in the ACK TCS were low at all speeds and all concentrations. For example, for $\mathrm{SiO}_{2}$ nanofluid $(0.05$ vol\%), power reductions are more evident at speeds above 800 RPM.
As shown in Fig. 11, the $\mathrm{SiO}_{2}$ WBM nanofluid trends are quite different when compared to the two previous nanofluids. At lower concentrations of 0.05 and $0.1 \%$, they showed increasing power-saving trends by increasing speed while decreasing power-saving trends for higher concentrations, although the total power saving is lower compared with the two other nanofluids. For example, at speed of 1600 RPM, the power saving of 26.76, 17.69, 12.93 and $13.15 \%$ is achieved at $\mathrm{SiO}_{2}$ concentrations of $0.05,0.1,0.5$ and $1.0 \%$, respectively. 
Fig. 8 Total power consumption of $\mathrm{TiO}_{2} \mathrm{WBM}$ nanofluids in the ACK TCS
Fig. 9 Total power saving of $\mathrm{TiO}_{2}$ WBM nanofluids in the ACK TCS
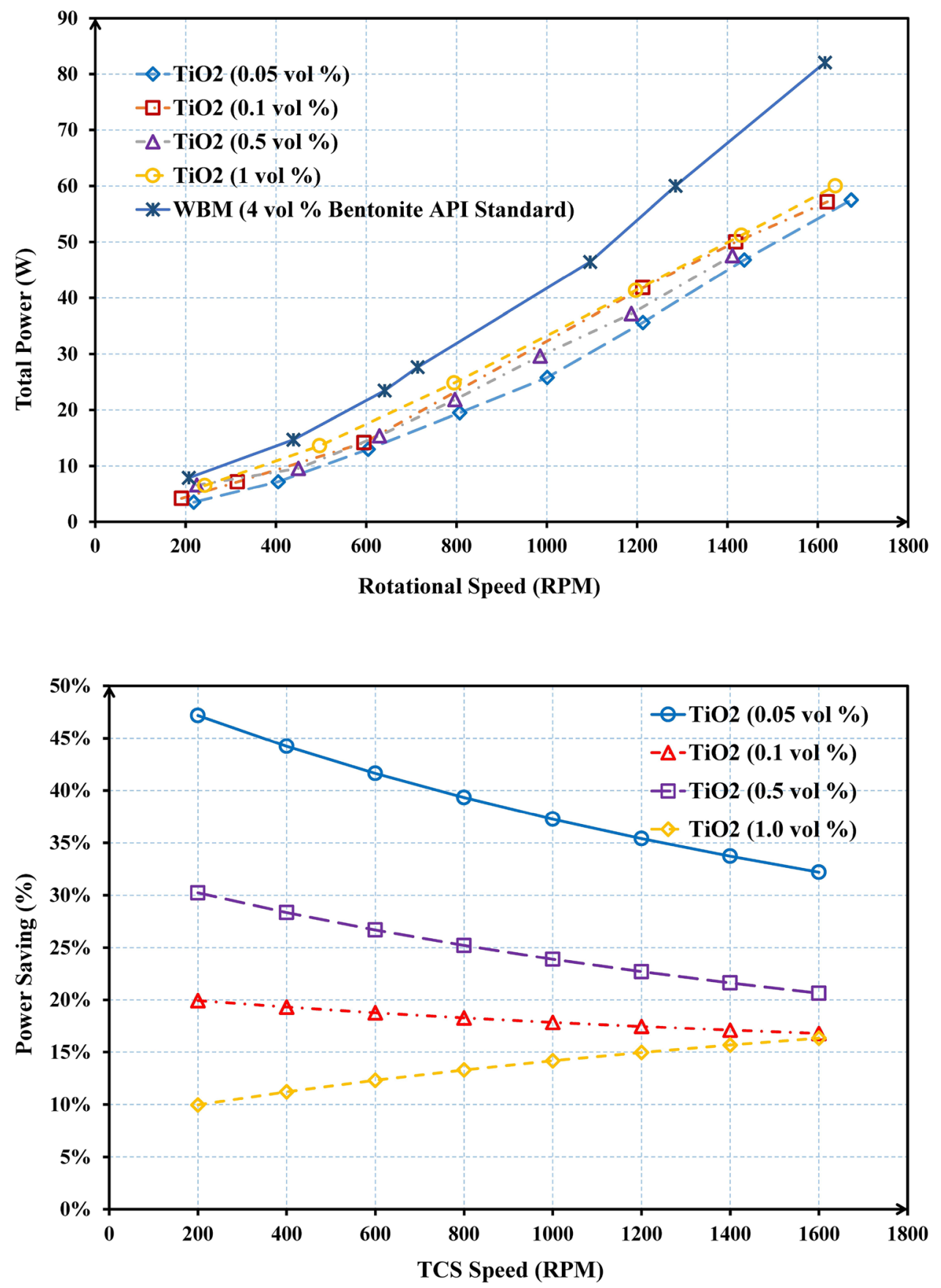

\section{Comparison of power saving of all nanofluids}

\section{Nanofluid concentration of $0.05 \%$}

Figure 12 compares power saving of different nanofluids at $0.05 \%$ concentration. As seen in Fig. $12, \mathrm{TiO}_{2}$ nanofluid saved the highest power among two other nanofluid at all speeds, followed by $\mathrm{Al}_{2} \mathrm{O}_{3}$ and $\mathrm{SiO}_{2}$ WBM nanofluids as second and third best, respectively. Trends for power saving are decreasing for $\mathrm{TiO}_{2}$ and $\mathrm{Al}_{2} \mathrm{O}_{3}$ but increasing for
$\mathrm{SiO}_{2}$ nanofluids by increasing speed of the TCS at the low concentration of $0.05 \%$.

\section{Nanofluid concentration of $0.1 \%$}

Figure 13 shows different trends for power saving of nanofluids at $0.1 \%$ concentration. As observed here, $\mathrm{Al}_{2} \mathrm{O}_{3}$ nanofluid showed better power saving at all speeds when compared to the other two nanofluids, with $\mathrm{TiO}_{2}$ and $\mathrm{SiO}_{2} \mathrm{WBM}$ nanofluids taking the next levels. However, power saving of all nanofluids is lower than those observed in Fig. 12. Trends 
Fig. 10 Total power consumption of $\mathrm{SiO}_{2}$ WBM nanofluids in the ACK TCS
Fig. 11 Total power saving of $\mathrm{SiO}_{2}$ WBM nanofluids in the ACK TCS
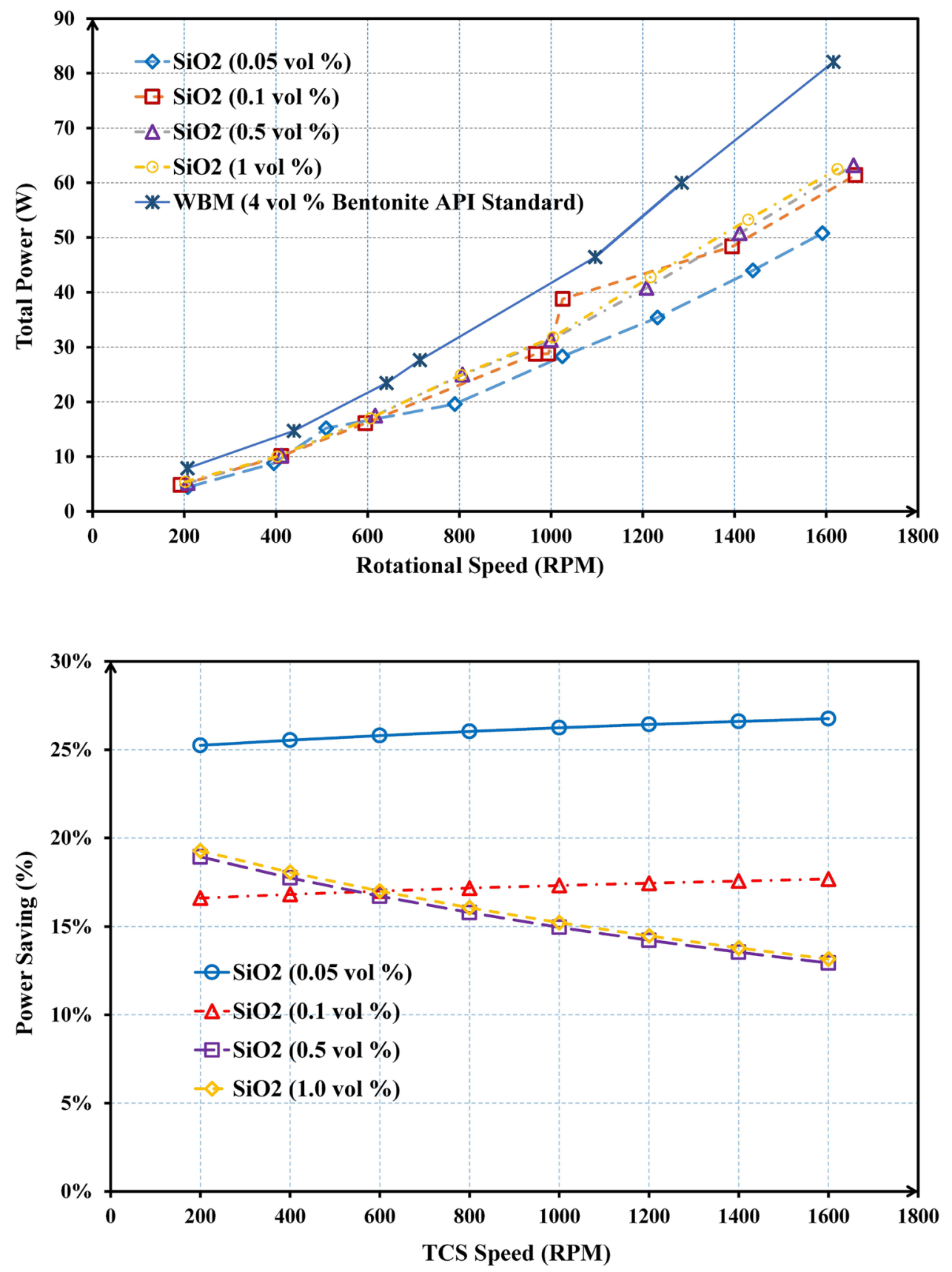

for decreasing power saving for $\mathrm{TiO}_{2}$ and $\mathrm{Al}_{2} \mathrm{O}_{3}$ but increasing for $\mathrm{SiO}_{2}$ are also observed at a concentration of $0.1 \%$.

\section{Nanofluid concentration of $0.5 \%$}

As illustrated in Fig. 14, once again $\mathrm{TiO}_{2}$ shows better power saving compared two other nanofluids at concentration of $0.5 \%$. At this concentration, all nanofluids show decreasing trends by increasing speed of TCS.

\section{Nanofluid concentration of $1.0 \%$}

As shown in Fig. 15, $\mathrm{Al}_{2} \mathrm{O}_{3}$ nanofluid saved more power with $\mathrm{SiO}_{2}$ as the second best below 1200 RPM while $\mathrm{TiO}_{2}$ as the second best at speeds beyond 1200 RPM. Not a single nanofluid showed good performance at different concentrations. Hence, nanoparticles should be wisely selected based on certain desirable rheology characteristics and power saving studied here. 
Fig. 12 Total power saving of different WBM nanofluids at $0.05 \%$ concentration
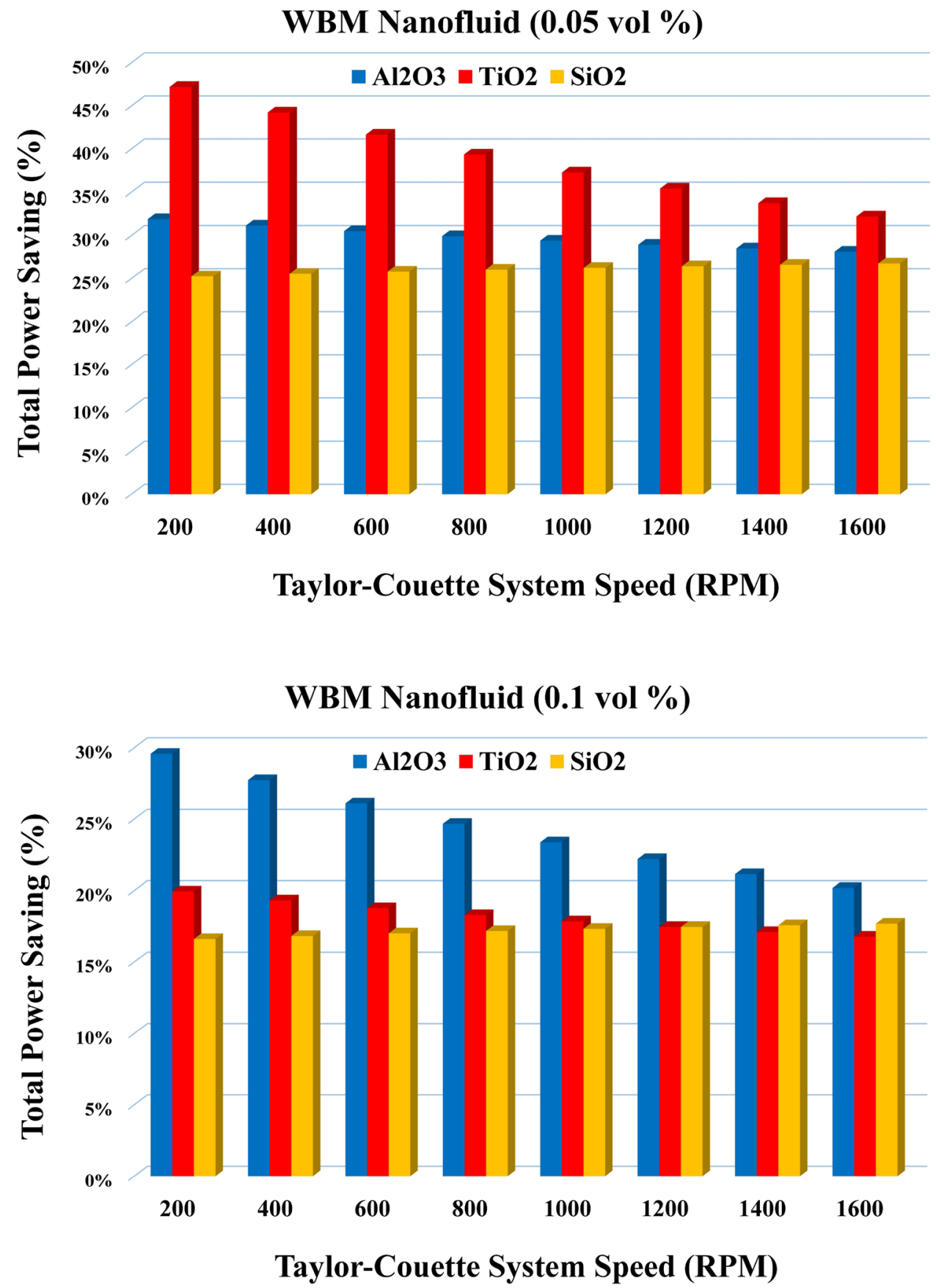

\section{Conclusions}

In oil and gas wellbore drilling, energy-efficient drilling fluids are desirable for reducing exploitation costs and also enhanced rheology characteristics. In this paper, our focus was on energy saving of nanofluids at low concentrations. We selected environment friendly WBM to be improved by adding three type nanoparticles $\mathrm{Al}_{2} \mathrm{O}_{3}, \mathrm{TiO}_{2}$ and $\mathrm{SiO}_{2}$ at volume fraction of $0.05,0.1,0.5$ and 1.0. General recommendation from the literature suggested to use concentrations between 0.5 and $1 \%$ while this study showed that lower concentrations of $0.05-0.1 \%$ can substantially reduce power consumption. There are, however, other rheology parameters of interest which should be considered in future studies. From power-saving aspect, this work is concluded as follows:

- $\mathrm{TiO}_{2}$ nanofluids have better power saving at lower concentrations of 0.05 and $0.1 \%$ compared with counterpart $\mathrm{Al}_{2} \mathrm{O}_{3}$ and $\mathrm{SiO}_{2}$ nanofluids. 
Fig. 14 Total power saving of different WBM nanofluids at $0.5 \%$ concentration

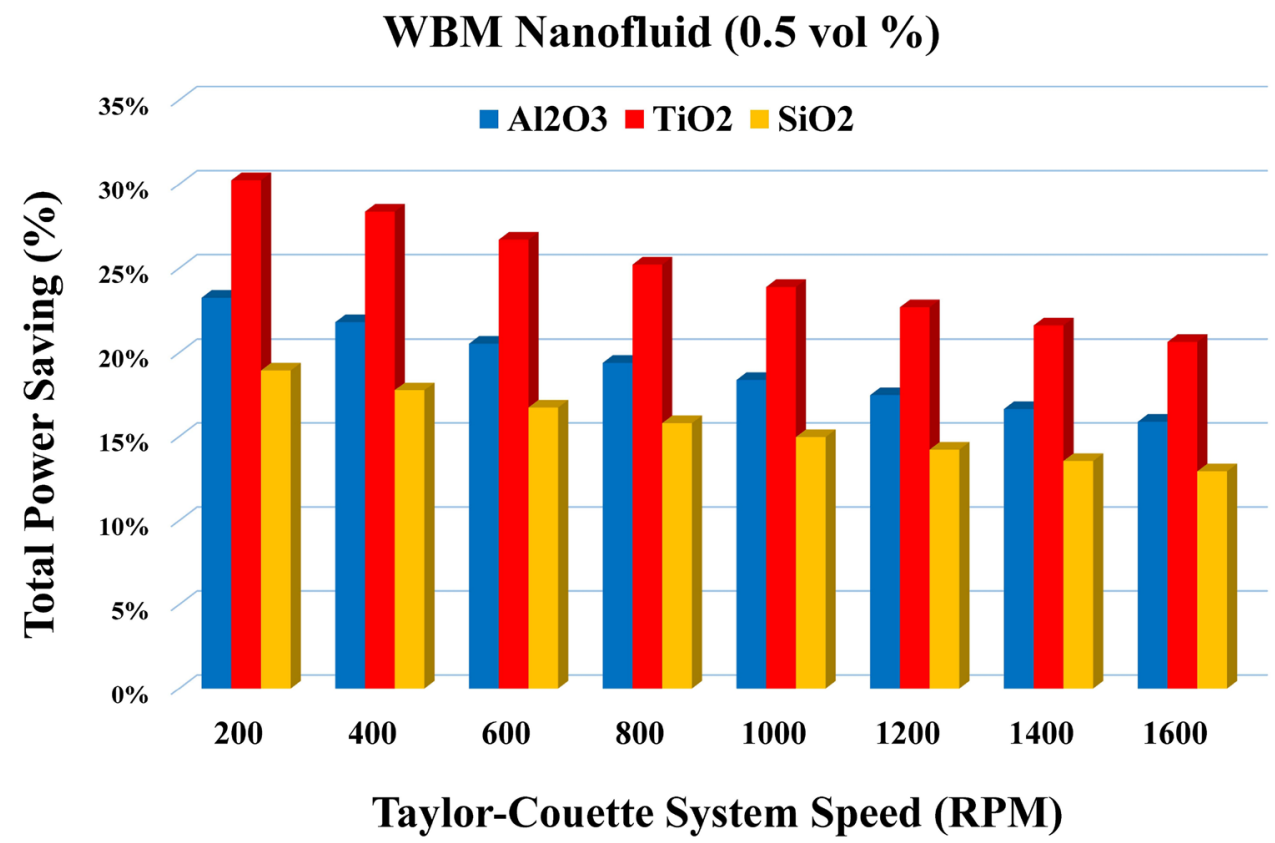

Taylor-Couette System Speed (RPM)

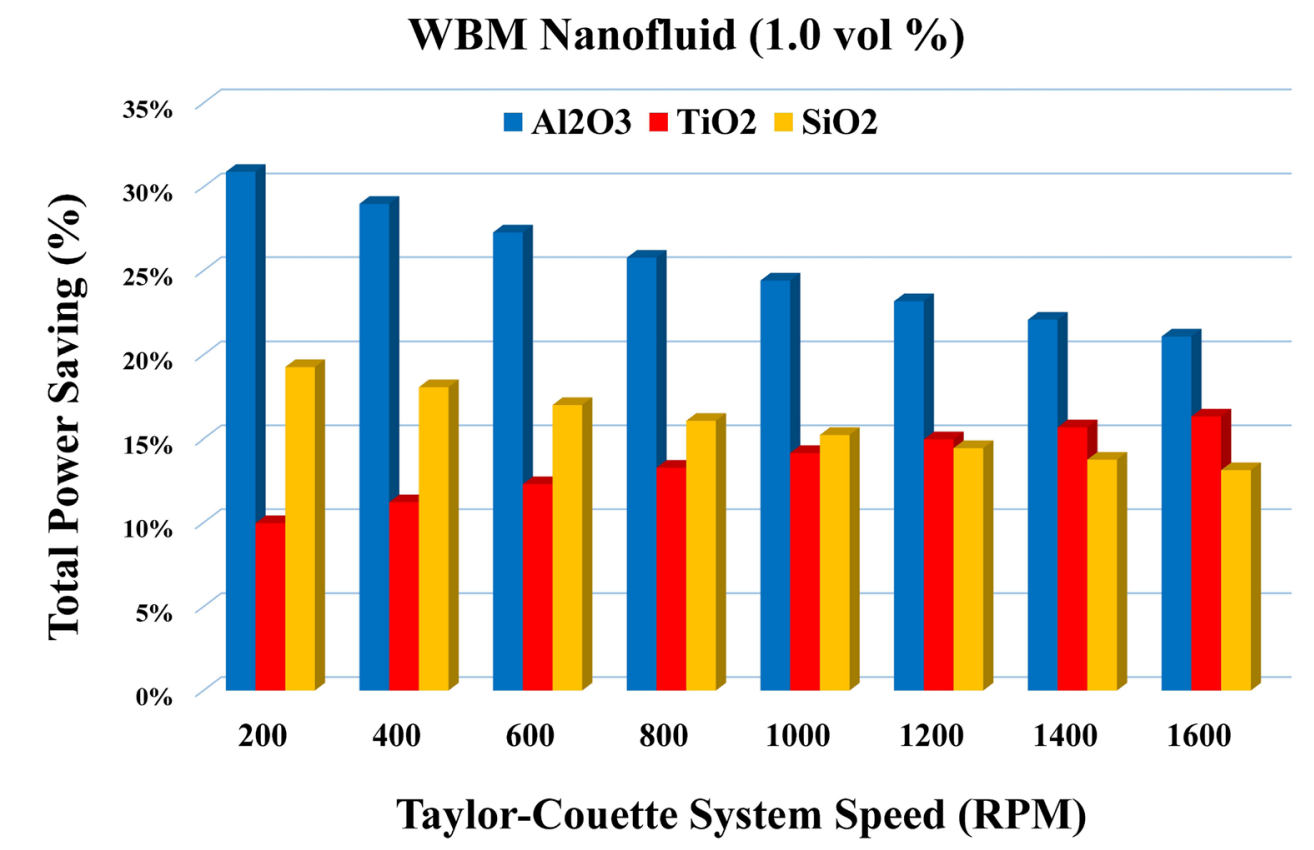

Fig. 15 Total power saving of different WBM nanofluids at $0.5 \%$ concentration
- $\mathrm{Al}_{2} \mathrm{O}_{3}$ nanofluids at concentrations of 0.5 and $1.0 \%$ performed better power saving than other studied nanofluids.

- Maximum power saving of $47.18 \%$ was obtained by $\mathrm{TiO}_{2}$ (0.05 vol\%) nanofluid at low speed of 200 RPM.

This study indicated that very low concentrated nanofluids may have different characteristics so that lower intervals and more experimental works are needed to discover full behavior of nanofluids at different speeds as it was found in the literature toward the TCS flow patterns and flow behavior. Drilling fluids are non-Newtonian which adds more complexity to such studies. Effects of other important parameters such as temperature, surfactant, $\mathrm{pH}$, nanoparticle size and shape will certainly need a long and continuous patient work in this field. One of the limitations of the ACK TCS is that we cannot test nanofluids at a fixed speed due to the chosen DC servo motor. We aimed to use a stepper motor in new versions with capability of setting on fixed speeds. The present work can be extended for oil-based muds (OBM) too. 
Acknowledgements This work was funded by Kuwait Foundation for Advancement of Science (KFAS) under Grant No. PR18-15EP-01. Second author wishes to express his thanks to Dr Daniel Borrero Echeverry from Willamette University for providing with his TCS CAD drawings.

Open Access This article is licensed under a Creative Commons Attribution 4.0 International License, which permits use, sharing, adaptation, distribution and reproduction in any medium or format, as long as you give appropriate credit to the original author(s) and the source, provide a link to the Creative Commons licence, and indicate if changes were made. The images or other third party material in this article are included in the article's Creative Commons licence, unless indicated otherwise in a credit line to the material. If material is not included in the article's Creative Commons licence and your intended use is not permitted by statutory regulation or exceeds the permitted use, you will need to obtain permission directly from the copyright holder. To view a copy of this licence, visit http://creativecommons.org/licenses/by/4.0/.

\section{References}

13B-1 AR (2009) Recommended practice for field testing water-based drilling fluids. API 4th Edition

Afzal A, Nawfal I, Mahbubul IM et al (2019) An overview on the effect of ultrasonication duration on different properties of nanofluids. J Therm Anal Calorim 135:393-418. https://doi.org/10.1007/ s10973-018-7144-8

Aftab A, Ismail AR, Ibupoto ZH, Akeiber H, Malghani MGK (2017) Nanoparticles based drilling muds a solution to drill elevated temperature wells: a review. Renew Sustain Energy Rev 76:1301-1313

Aluminum Oxide $\left(\mathrm{Al}_{2} \mathrm{O}^{3}\right)$ Nanopowder (alpha, 99.5\%, 27-43 nm) (2019) Nanostructured \& Amorphous Materials, Inc, https://www. nanoamor.com/inc/sdetail/23069. Accessed Oct 2019

Almutairi K, Mostafaeipour A, Jahanshahi E, Jooyandeh E, Himri Y, Jahangiri M et al (2021) Ranking locations for hydrogen production using hybrid wind-solar: a case study. Sustainability 13:4524

Almutairi K, Hosseini Dehshiri SS, Hosseini Dehshiri SJ, Mostafaeipour A, Issakhov A, Techato K (2021) A thorough investigation for development of hydrogen projects from wind energy: a case study. Int J Hydrogen Energy 46:18795-18815

Amanullah M, Al-Tahini AM (2009) Nano-technology-its significance in smart fluid development for oil and gas field application. In: SPE Saudi Arabia section technical symposium: society of petroleum engineers

Andereck CD, Liu SS, Swinney HL (1986) Flow regimes in a circular Couette system with independently rotating cylinders. J Fluid Mech 164:155-183

Arias BM (2015) Torque measurement in turbulent Couette-Taylor flows (Doctoral dissertation, Université du Havre)

Azaditalab M, Houshmand A, Sedaghat A (2016) Numerical study on skin friction reduction of nanofluid flows in a Taylor-Couette system. Tribol Int 94:329-335

Booser ER (1984) CRC handbook of lubrication. Theory and practice of tribology: volume II: theory and design, USA

Chai YH, Yusup S, Chok VS (2015) A review on nanoparticle addition in base fluid for improvement of biodegradable ester-based drilling fluid properties. Chem Eng Trans 45:1447-1452

Chhabra RP, Richardson JF (1999) Non-Newtonian flow in the process industries: fundamentals and engineering applications. Butterworth-Heinemann, Oxford

Chossat P, Iooss G (2012) The Couette-Taylor problem. Springer, Berlin
Couette M (1890) Studies relating to the friction of liquids. Ann Chim Phys 21:433-510

Fakoya MF, Ahmed RM (2018) A generalized model for apparent viscosity of oil-based muds. J Pet Sci Eng 165:777-785

Grossmann S, Lohse D, Sun C (2016) High-Reynolds number TaylorCouette turbulence. Annu Rev Fluid Mech 48:53-80

Huang J, Wang X, Long Q, Wen X, Zhou Y, Li L (2009) Influence of $\mathrm{pH}$ on the stability characteristics of nanofluids. In: 2009 Symposium on photonics and optoelectronics. IEEE, pp 1-4

Jabrayilov E (2014) Friction reduction by using nanoparticles in oilbased mud: Institutt for petroleumsteknologi og anvendt geofysikk

Jahns C (2014) Friction reduction by using nano-fluids in drilling. Institutt for petroleumsteknologi og anvendt geofysikk

Kalbasi R, Jahangiri M, Mosavi A, Dehshiri SJH, Dehshiri SSH, Ebrahimi $\mathrm{S}$ et al (2021) Finding the best station in Belgium to use residential-scale solar heating, one-year dynamic simulation with considering all system losses: economic analysis of using ETSW. Sustain Energy Technol Assess 45:101097

Katende A, Boyou NV, Ismail I, Chung DZ, Sagala F, Hussein N et al (2019) Improving the performance of oil based mud and water based mud in a high temperature hole using Nanosilica nanoparticles. Colloids Surf A Physicochem Eng Asp 577:645-673

Kristensen A (2013) Flow properties of water-based drilling fluids: Institutt for petroleumsteknologi og anvendt geofysikk

Larson JW (1983) Predicting the properties of mixture-mixture rules in science and engineering, NIELSEN, LE. American Chemical Society, Washington, DC

Luo T, Wei X, Huang X, Huang L, Yang F (2014) Tribological properties of $\mathrm{Al}_{2} \mathrm{O}_{3}$ nanoparticles as lubricating oil additives. Ceram Int 40:7143-7149

Mostafaeipour A, Hosseini Dehshiri SJ, Hosseini Dehshiri SS, Jahangiri M, Techato K (2020) A thorough analysis of potential geothermal project locations in Afghanistan. Sustainability 12:8397

Mostafaeipour A, Dehshiri SJH, Dehshiri SSH, Jahangiri M (2020) Prioritization of potential locations for harnessing wind energy to produce hydrogen in Afghanistan. Int J Hydrogen Energy 45:33169-33184

Mostafaeipour A, Jahangiri M, Haghani A, Dehshiri SJH, Dehshiri SSH, Sedaghat A et al (2020) Statistical evaluation of using the new generation of wind turbines in South Africa. Energy Rep 6:2816-2827

Mostafaeipour A, Dehshiri SJH, Dehshiri SSH (2020) Ranking locations for producing hydrogen using geothermal energy in Afghanistan. Int J Hydrogen Energy 45:15924-15940

Pakdaman E, Osfouri S, Azin R, Niknam K, Roohi A (2019) Improving the rheology, lubricity, and differential sticking properties of water-based drilling muds at high temperatures using hydrophilic gilsonite nanoparticles. Colloids Surf A Physicochem Eng Asp 582:123930

Parizad A, Shahbazi K, Tanha AA (2018) Enhancement of polymeric water-based drilling fluid properties using nanoparticles. J Pet Sci Eng 170:813-828

Podryabinkin E, Rudyak V, Gavrilov A, May R (2013) Detailed modeling of drilling fluid flow in a wellbore annulus while drilling. In: International conference on offshore mechanics and arctic engineering. American Society of Mechanical Engineers, $p$ V006T11A13

Ponmani S, Nagarajan R, Sangwai JS (2016) Effect of nanofluids of $\mathrm{CuO}$ and $\mathrm{ZnO}$ in polyethylene glycol and polyvinylpyrrolidone on the thermal, electrical, and filtration-loss properties of waterbased drilling fluids. SPE J 21:405-415

Rashidi M, Sedaghat A, Misbah B, Sabati M, Vaidyan K (2020) Developing a Taylor-Couette stand-alone viscometer for testing drilling fluids with turbulent nano fluid flow and testing stability of different shale materials. Kuwait Foundation for the Advancement of Science (KFAS). August 2020; Grant No. PR18-15EP-01

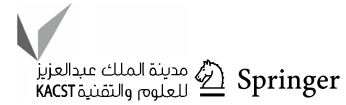


Rashidi M, Sedaghat A, Misbah B, Sabati M, Vaidyan K (2020) Experimental study on energy saving and friction reduction of $\mathrm{Al}_{2} \mathrm{O}_{3}$-WBM nanofluids in a high-speed Taylor-Couette flow system. Tribol Int 154:106728

Shah SN, Shanker NH, Ogugbue CC (2010) Future challenges of drilling fluids and their rheological measurements. In: AADE fluids conference and exhibition, Houston, TX

Silicon Oxide Nanopowder/SiO $/ \mathrm{S}_{2}$ Nanoparticles $\left(\mathrm{SiO}_{2}, 99.5+\%\right.$, 15-20nm, S-type, Spherical) (2019) US Research Nanomaterials, Inc., The Advanced Nanomaterials Provider. https://www.usnano. com/. Accessed Oct 2019

Tang Z, Li S (2014) A review of recent developments of friction modifiers for liquid lubricants (2007-present). Curr Opin Solid State Mater Sci 18:119-139

Taylor GIVIII (1923) Stability of a viscous liquid contained between two rotating cylinders. Philos Trans R Soc Lond Ser A Pap Math Phys Charact 223:289-343

van Gils DPM (2011) Highly Turbulent Taylor-Couette flow

Vryzas Z, Kelessidis VC (2017) Nano-based drilling fluids: a review. Energies 10:540

Vryzas Z, Mahmoud O, Nasr-El-Din HA, Kelessidis VC (2015) Development and testing of novel drilling fluids using $\mathrm{Fe}_{2} \mathrm{O}_{3}$ and $\mathrm{SiO}_{2}$ nanoparticles for enhanced drilling operations. In: International petroleum technology conference

Vryzas Z, Zaspalis V, Nalbantian L, Mahmoud O, Nasr-El-Din HA, Kelessidis VC (2016) A comprehensive approach for the development of new magnetite nanoparticles giving smart drilling fluids with superior properties for HP/HT applications. In: International petroleum technology conference

Vryzas Z, Kelessidis VC, Bowman MBJ, Nalbantian L, Zaspalis V, Mahmoud $O$ et al (2017) Smart magnetic drilling fluid with insitu rheological controllability using $\mathrm{Fe}_{3} \mathrm{O}_{4}$ nanoparticles. In: SPE Middle East oil \& gas show and conference: society of petroleum engineers

Wang, H. (2015). Experimental and numerical study of Taylor-Couette flow. Iowa State University

Wiener O (1912) Die Theorie des Mischkorpers fur das Feld der stationaren Stromung. Abhandlungen Der Sachsischen Gesellschaft Der Akademischen Wissenschaften in Mathematik Und Physik 32:507-604

Yeu WJ, Katende A, Sagala F, Ismail I (2019) Improving hole cleaning using low density polyethylene beads at different mud circulation rates in different hole angles. J Nat Gas Sci Eng 61:333-343

Yu W, Xie H (2012) A review on nanofluids: preparation, stability mechanisms, and applications. J Nanomater. https://doi.org/10. $1155 / 2012 / 435873$

Yu W, France DM, Singh D, Timofeeva EV, Smith DS, Routbort JL (2010) Mechanisms and models of effective thermal conductivities of nanofluids. J Nanosci Nanotechnol 10:4824-4849

Publisher's Note Springer Nature remains neutral with regard to jurisdictional claims in published maps and institutional affiliations.

\section{Authors and Affiliations}

\section{Masoud Rashidi ${ }^{1}$ Ahmad Sedaghat ${ }^{2} \cdot$ Biltayib Misbah $^{1} \cdot$ Mohammad Sabati $^{3} \cdot$ Koshy Vaidyan $^{1}$. Ali Mostafaeipour ${ }^{4,5,6}$ (1) Seyyed Shahabaddin Hosseini Dehshiri ${ }^{7} \cdot$ Khalid Almutairi $^{8} \cdot$ Alibek Issakhov $^{9,10}$. Seyed Amir Abbas Oloomi ${ }^{11}$. Mahdi Ashtian Malayer ${ }^{12}$. Joshuva Arockia Dhanraj ${ }^{5,6,13}$}

Masoud Rashidi

rashidimasoud@yahoo.com

Ahmad Sedaghat

a.sedaghat@ack.edu.kw

Biltayib Misbah

b.biltayib@ack.edu.kw

Mohammad Sabati

m.sabati@ack.edu.kw

Koshy Vaidyan

k.vaidyan@ack.edu.kw

Seyyed Shahabaddin Hosseini Dehshiri

hosseini.ssa@mech.sharif.edu

Khalid Almutairi

khalid.almutairi@uhb.edu.sa

Alibek Issakhov

alibek.issakhov@kaznu.kz

Seyed Amir Abbas Oloomi

Amiroloomi@iauyazd.ac.ir

Mahdi Ashtian Malayer

mahdiashtian@yahoo.com

Joshuva Arockia Dhanraj

joshuva1991@gmail.com
1 Petroleum Engineering Department, Australian College of Kuwait, Kuwait, Kuwait

2 Mechanical Engineering Department, Australian College of Kuwait, Kuwait, Kuwait

3 Electrical Engineering Department, Australian College of Kuwait, Kuwait, Kuwait

4 Industrial Engineering Department, Yazd University, Yazd, Iran

5 Faculty of Environmental Management, Prince of Songkla University, HatYai, Songkhla 90112, Thailand

6 Environmental Assessment and Technology for Hazardous Waste Management Research Center, Faculty of Environmental Management, Prince of Songkla University, Songkhla 90112, Thailand

7 Department of Mechanical Engineering, Sharif University of Technology, Tehran, Iran

8 Mechanical Engineering Technology, Community College, University of Hafr Al Batin, Hafr Al Batin, Saudi Arabia

9 Faculty of Mechanics and Mathematics, Department of Mathematical and Computer Modelling, Al-Farabi Kazakh National University, 050040 Almaty, Kazakhstan

10 Department of Mathematics and Cybernetics, Kazakh-British Technical University, 50000 Almaty, Kazakhstan 
11 Department of Mechanical Engineering, Yazd Branch, Islamic Azad University, Yazd, Iran

12 Young Researchers and Elite Club, Yazd Branch, Islamic Azad University, Yazd, Iran
13 Centre for Automation and Robotics (ANRO), Department of Mechanical Engineering, Hindustan Institute of Technology and Science, Padur, Chennai 603103, India 